\title{
Optimization of Suspender Cable Force of Long-Span Concrete Arch Bridges Based on Embedded Matrix Method
}

\author{
Kaizhong Xie $\mathbb{D},{ }^{1,2}$ Mengsheng Yu $\mathbb{D},,^{1}$ Xinyu Yao $\mathbb{D},,^{3}$ Longlin Wang $\mathbb{D},,^{3}$ Tianzhi Hao $\mathbb{D},{ }^{4}$ \\ and Hua Wang $\mathbb{B D}^{3}$
}

${ }^{1}$ College of Civil Engineering and Architecture, Guangxi University, Nanning 530004, China

${ }^{2}$ Large-Span Arch Bridge Engineering Technology Center, Nanning 530004, China

${ }^{3}$ Guangxi Transportation Science and Technology Group Co., Ltd., Nanning 530007, China

${ }^{4}$ Guangxi Beitou Traffic Maintenance Technology Group Co., Ltd., Nanning 530029, China

Correspondence should be addressed to Mengsheng Yu; xiaoluo19890316@163.com

Received 30 July 2021; Revised 15 December 2021; Accepted 4 January 2022; Published 18 January 2022

Academic Editor: Keerthan Poologanathan

Copyright ( $\odot 2022$ Kaizhong Xie et al. This is an open access article distributed under the Creative Commons Attribution License, which permits unrestricted use, distribution, and reproduction in any medium, provided the original work is properly cited.

In order to simplify the completion process of cable force optimization and adjustment in long-span concrete-filled steel tube arch bridges, a new method was proposed in the present study. To this end, a reasonable completion cable force calculation method was proposed based on the influence matrix principle of cable force optimization. Then combined with the mechanical characteristics of concrete-filled steel tube arch bridge, the weighted matrix was introduced to simplify the influence matrix of cable force and optimize the suspender cable force. The performed comparative study showed that the maximum difference of single cable force between the measured and calculated values is less than $5 \%$, and the calculation error satisfies the requirements of the specification. It is concluded that the proposed method can accurately control the suspender tension construction in the arch bridge, optimize the cable force of long-span concrete filled-steel tube arch bridge, and realize the comparison and selection of various optimization schemes. The research results have been successfully applied to the suspender force adjustment of Third Pingnan Bridge, which greatly simplifies the adjustment steps and the total cable force difference in the whole bridge is $1.37 \%$, the difference between the measured and designed suspender tensions of Heshan Hongshui River Bridge at completion state is less than 2\%. The successful application of this method effectively saves the labor and material cost of suspender adjustment and further enhances the superiority of steel tube concrete arch bridge. The proposed method is expected to be an excellent choice to monitor constructions, adjust the bridge completion stage, and provide a reference for the suspender tension construction control of similar bridges.

\section{Introduction}

With the improvement of the design theories and construction methods and the advent of novel materials, the span of concrete-filled steel tubular arch bridges has increased significantly. In the past two decades, more than 250 concrete-filled steel tube arch bridges with a span of more than $50 \mathrm{~m}$, including 7 bridges with a span of more than $400 \mathrm{~m}$ have been constructed in China [1-5]. On the other hand, as the span of the concrete-filled steel tube arch bridge increases, adjustment of the cable force becomes more complex. Therefore, optimizing the suspender cable force of the arch bridge is the most challenging issue in monitoring the arch bridge construction process [6-9].

Previous literature indicates that most investigations on the optimization of suspender cable force of concrete-filled steel tube arch bridges are mainly focused on the optimization and realization of the cable force. In this regard, cable force optimization has been studied comprehensively $[10,11]$. Because under the reasonable arch forming state, the arch bridge mainly produces horizontal thrust. Due to the existence of this horizontal thrust, the bending moment of the arch will be much smaller than that of the beam of the same span, and the whole arch will mainly bear pressure. 
Therefore, the main hypothesis in these investigations is that under the action of dead and live loads, the bending stress of the arch rib and beam is small and the stress distribution is uniform $[12,13]$. However, considering the limitations of design, construction, and structural parameters in engineering problems, it is a challenge to ensure that the cable force is consistent with the designed tension after hoisting the main beam and second-stage pavement of the bridge. Accordingly, it is necessary to adjust the cable force repeatedly in each stage. In this regard, numerous methods, including the influence matrix method [14], forward iteration method [15], and inversion analysis method [16], have been proposed so far. In the forward iteration method and inversion analysis method, stress and structural deformation analyses are conducted according to the forward and inversion loading sequences, respectively. Consequently, the tension sequence should be strictly followed in these methods. As a result, unreasonable selection of the suspender tension sequence should be adjusted by repeated tension to achieve the designed cable force. Although this is an effective method, it has a complex construction and unstable accuracy [17]). On the other hand, the main objective of the influence matrix method is to optimize and adjust the cable force based on the influence degree matrix of the suspender force at different positions on the adjacent suspenders. Therefore, there is no need to consider the construction sequence in this method. However, the tension force of all suspenders should be adjusted by this method, which is a challenging task in a real construction process. Some scholars $[18,19]$ applied the weighted matrix into the calculation of suspender cable force adjustment of an arch bridge and modified the influence matrix of upstream and downstream into the influence matrix of other suspender cable forces in the case of single suspender cable tension. Further investigations revealed that the main drawback of this method is the necessity of adjusting the suspender cable force of the whole bridge, which increases the construction time.

This paper aims at proposing an adjustment method for suspender tension of CFST (concrete-filled steel tube) by improving algorithm based on conventional influence matrix. The proposed method is then verified by data collecting from a supporting project of a CFST (concretefilled steel tube) with the span of $575 \mathrm{~m}$. The conventional cable adjustment scheme needs to adjust the cable force of the suspender of the whole bridge, and the tensioning force of all suspenders must be adjusted. In the actual construction process, the suspender adjustment is difficult and the construction period is long. In order to simplify the cable force optimization and cable adjustment in longspan concrete-filled steel tube arch bridges, a new method was proposed for cable force optimization of long-span concrete-filled steel tube arch bridge based on the influence matrix principle of cable force optimization. Then the proposed method was verified through experiments. That is, only a few cables with great influence need to be adjusted to complete the cable force adjustment of the whole bridge. This method is expected to optimize the completion cable force of the long-span concrete-filled steel tube arch bridge conveniently so that it can be applied in the construction monitoring and adjustment of the completion stage. The obtained results reveal that measuring error of cable force meets the requirements of the specification. The proposed method is expected to provide a reference for the suspender tension construction control of the same type of bridge.

\section{Establishment of the Optimization Method for Suspender Cable Force of Concrete-Filled Steel Tube Arch Bridge}

2.1. Calculation of Reasonable Completion Cable Force Adjustment Based on the Influence Matrix Method. The reasonable completion state of a concrete-filled steel tube arch bridge should not only meet the design requirements of cable force control objectives but also meet the design requirements of other finished state control objectives such as arch rib axis deviation, main beam deflection, arch rib, and girder bending moment $[11,12]$. Therefore, based on the influence matrix method, various physical quantities that may affect the problem are considered as the control objective $\{\Delta R\}$. Then the governing equation of suspender cable force adjustment of concrete-filled steel tube arch bridge can be established in the form below:

$$
[A]\{\Delta T\}_{n}=\{\Delta R\}_{m},
$$

where $[A]$ is the influence matrix of the cable force adjustment on the control objective, $\{\Delta T\}$ denotes the cable force adjustment of the completion state, and $\{\Delta R\}$ is the control objective adjustment of the completion state. Moreover, $m$ and $n(m>n)$ reflect the element number of $\{\Delta R\}$ and $\{\Delta T\}$, respectively.

In order to obtain the optimal solution, the number of equations should exceed the number of adjusted cable forces. Based on the least square method, the square error function $Q$ can be defined in the form below:

$$
\begin{aligned}
& Q=\|[A]\{\Delta T\}-\{\Delta R\}\|^{2}, \\
& Q=\sum_{i=1}^{m}\left[\Delta R_{i}-\sum_{j=1}^{n} \Delta \alpha_{i j} \cdot \Delta T_{j}\right]^{2},
\end{aligned}
$$

where $\Delta \alpha_{i j}$ denotes the unit change of the $j$ th control objective caused by the unit adjustment of the $i$ th suspender cable force.

According to the extremum theorem, when the objective function $Q(\{\Delta T\})$ took the minimum value, $\Delta T_{k}$ should satisfy the following equations:

$$
\begin{aligned}
& \frac{\partial Q(\{\Delta T\})}{\partial \Delta T_{k}}=0(k=1,2, \ldots, n), \\
& 2 \sum_{i=1}^{m}\left\{\left[\Delta R_{i}-\sum_{j=1}^{n} \Delta \alpha_{i j} \cdot \Delta T_{j}\right] \cdot\left(-\alpha_{i k}\right)\right\}=0 .
\end{aligned}
$$

(5) can be simplified in the form below: 


$$
\sum_{j=1}^{n} \sum_{i=1}^{m} \Delta \alpha_{i j} \cdot \Delta T_{j}=\sum_{i=1}^{m} \alpha_{i k} \Delta R_{i}
$$

Moreover, (3) can be rewritten in the matrix form:

$$
[A]^{T}[A]\{\Delta T\}=[A]^{T}\{\Delta R\} .
$$

(5) is a linear set of equations with " $n$ " number of unknowns and " $n$ " number of equations. It should be indicated that $\{\Delta T\}$ can be calculated through (8). The required adjustment of control objective at reasonable completion state $\{R\}$ could be calculated in the form below:

$$
\{R\}=\left\{R_{0}\right\}+[A]\{\Delta T\},
$$

where $\left\{R_{0}\right\}$ is the value of the control objective at a reasonable completion state before adjustment. Usually, the control objective could be taken as the suspender cable force of the arch bridge. Considering the design and construction requirements, axis deviation of the arch rib, deflection of the main beam, and bending moment of the arch rib and the main beam can be selected as the main control objectives.

2.2. Optimization of the Completion Cable Force Based on the Improved Influence Matrix. In the present study, the cable force is selected as the control objective at a reasonable completion state. In this regard, the completion cable force adjustment function could be established based on (8):

$$
\begin{aligned}
\{\Delta P\} & =\left\{\Delta P_{L}\right\}-\left\{\Delta P_{s}\right\} \\
& =[M]\{\Delta T\},
\end{aligned}
$$

where

$$
[M]=\left[\begin{array}{cccc}
\Delta \delta_{11} & \Delta \delta_{12} & \cdots & \Delta \delta_{1 n} \\
\Delta \delta_{21} & \Delta \delta_{22} & \cdots & \Delta \delta_{2 n} \\
\vdots & \ddots & \ddots & \vdots \\
\Delta \delta_{n 1} & \cdots & \Delta \delta_{11} & \Delta \delta_{n n}
\end{array}\right],
$$

where $\left\{\Delta P_{L}\right\}$ is the design completion cable force, $\left\{\Delta P_{s}\right\}$ denotes the suspender cable force before cable force adjustment, and $[M]$ is the influence matrix. Furthermore, $\Delta \delta_{i j}$ is the cable force variation of the $j$ th suspender, when the $i$ th suspender adjusts the unit cable force.

$[M]$ is a full rank matrix. (The rank of the matrix is equal to the number of rows.) Consequently, (9) could be left multiplied by $[M]^{-1}$ at both sides, and the cable force adjustment of each suspender could be obtained as follows:

$$
\{\Delta T\}=[M]^{-1}\left(\left\{\Delta P_{L}\right\}-\left\{\Delta P_{s}\right\}\right) .
$$

Then the final cable tension can be calculated in the form below:

$$
\{S\}=\{\Delta T\}+\left\{\Delta P_{s}\right\} .
$$

Most concrete-filled steel tube arch bridges have a weak asymmetric influence matrix. Therefore, when the beam arch stiffness of an arch bridge is relatively large, the values of counter-elements in the diagonal position are approximate. In order to reduce the number of cables and meet the allowable error margin, the positive definite diagonal matrix $[\lambda]$ was introduced in

$$
\begin{aligned}
\{\Delta P\} & =\left\{\Delta P_{L}\right\}-\left\{\Delta P_{s}\right\} \\
& =[\lambda][M]\{\Delta T\} .
\end{aligned}
$$

Since $[M]$ is a full rank matrix, (13) could be left multiplied by $[M]^{-1}[\lambda]^{-1}$ at both sides. Then the cable force adjustment of each suspender can be obtained as follows:

$$
\begin{aligned}
& \{\Delta T\}=[M]^{-1}[\lambda]^{-1}\{\Delta P\}, \\
& \{\Delta T\}=[M]^{-1}[\beta]^{-1}[\alpha]^{-1}\left(\left\{\Delta P_{L}\right\}-\left\{\Delta P_{s}\right\}\right),
\end{aligned}
$$

where $[\lambda]=[\alpha][\beta]$ is the weighted matrix. Meanwhile, $[\alpha]$ is the error control coefficient that transforms the weak asymmetric influence matrix with little difference into the symmetric influence matrix, and $[\beta]$ is the control degree coefficient considering the control objective. It is worth noting that a large weighting coefficient corresponds to a high degree of control to the objective so the adjusted value of the control objective approaches the control objective value. On the contrary, a small weighting coefficient corresponds to fast convergence and small number of adjusted cables. Accordingly, the optimal solution of cable force adjustment could be obtained by adjusting the weighting coefficient, and the objective cable force could be adjusted within a small range of cable force difference to achieve the designed cable force.

It should be indicated that in the proposed method, only the weighted matrix is introduced to solve the problem based on the influence matrix. The actual adjusted cable force is only related to the current cable force of the suspender, the influence matrix determined by the construction sequence, and the objective to be adjusted. More specifically, it is independent of the structure, including thrust arch and rigid/flexible tie.

2.3. Calculation Method. Based on the performed analysis, the optimal adjustment of suspender cable of concrete-filled steel tube arch bridge can be obtained by solving the cable force adjustment in the optimal weighting matrix [ $\lambda$ ]. In this regard, proper values of $[\alpha]$ and $[\beta]$ should be found to minimize the number of adjusted cable forces and satisfy the control accuracy. To this end, the following iterative process was adopted:

(1) Establish the finite element model considering the affecting parameters, including material characteristics, geometry, boundary conditions, and applied external loads on the concrete-filled steel tube arch bridge.

(2) Calculate the control objective value $\{R\}$ through (7) at reasonable a completion state.

(3) Determine the cable force influence matrix $[M]$ in the model and set the initial weighted matrices such as initial values of $[\alpha]$ and $[\beta]$ matrices. It is assumed that there are $k$ number of elements with weak asymmetry, while the number of initial 
transformations is $n=1$. After transforming the elements with weak asymmetry, the values of diagonal elements become equal and the symmetry matrix is achieved.

(4) Calculate the initial cable force adjustment $\{P\}_{1}$ using (15).

(5) Update the cable force of the finite element model according to the cable force adjustment $\{P\}_{1}$, calculate the completion cable force $\left\{T_{D}\right\}_{1}$, and calculate the difference between the control objective cable force $\{R\}$ and the completion cable force $\left\{T_{D}\right\}_{1}$.

(6) If the difference between the control objective cable force $\{R\}$ and the completion bridge cable force $\left\{T_{D}\right\}_{1}$ meet the requirements of the reasonable completion bridge state, the calculation is completed. Otherwise, return to step (3) and set $n=2, \ldots k$.

Figure 1 shows the flowchart of this iterative calculation. All calculations were carried out in the MATLAB environment, and the cable force adjustment of concrete-filled steel tube arch bridge was calculated [20].

\section{Comparative Analysis and Validation}

3.1. Engineering Overview and Modeling. The Third Pingnan Bridge is located $6 \mathrm{~km}$ upstream of Xijiang Bridge in Guigang City, China. It is a super large half-through concrete-filled steel tube arch bridge across the Xunjiang river. The main span, total length, and deck width of the bridge are $575 \mathrm{~m}, 1035 \mathrm{~m}$, and $36.5 \mathrm{~m}$, respectively. Moreover, there are two-way four lanes, two nonmotorized vehicle lanes, and two sidewalks on the bridge. The main arch rib was made of Q420qD steel plate, and C70 concrete was used in the pipe. Density and elastic modulus of C70 concrete are $25 \mathrm{kN} / \mathrm{m}^{3}$ and $3.7 \times 10^{4} \mathrm{MPa}$, respectively. Moreover, C30 concrete is used for the outer covering of the arch foot section. Density and elastic modulus of C30 concrete are $24 \mathrm{kN} / \mathrm{m}^{3}$ and $3.0 \times 10^{4} \mathrm{MPa}$, respectively. The main beam structure of the steel-concrete composite deck is adopted on the steel lattice beam with an elastic modulus of $2.06 \times 10^{5} \mathrm{MPa}$. In this section, C40 concrete with an elastic modulus of $3.25 \times 10^{4} \mathrm{MPa}$ was used. The main bridge deck pavement is made of $5 \mathrm{~cm}$ thick high-elastic high-viscosity Sam13 asphalt concrete. Moreover, $\varphi$ ( $\varphi$ Represents the diameter) $15.2 \mathrm{~mm}$ extrusion forming rod and cable body of epoxy sprayed steel strand are adopted on the main bridge suspender, which is anchored at the upper edge of the upper chord of the main arch and the lower flange of the main beam, respectively. Ultimate tensile strength of the steel strand is $1960 \mathrm{MPa}$, and the suspender spacing is $15.5 \mathrm{~m}$. Figure 2 shows that the sling above the sidewalk is protected and decorated by an outer muffle tube.

According to the design drawings of Third Pingnan Bridge, the finite element software MIDAS/Civic is used for simulation. The established finite model consists of 8,350 nodes and 15,156 elements. The main arch rib steel pipe and web member are simulated by steel pipe elements with different pipe diameters. The suspender is simulated by cable element. The bridge deck beam is simulated by beam

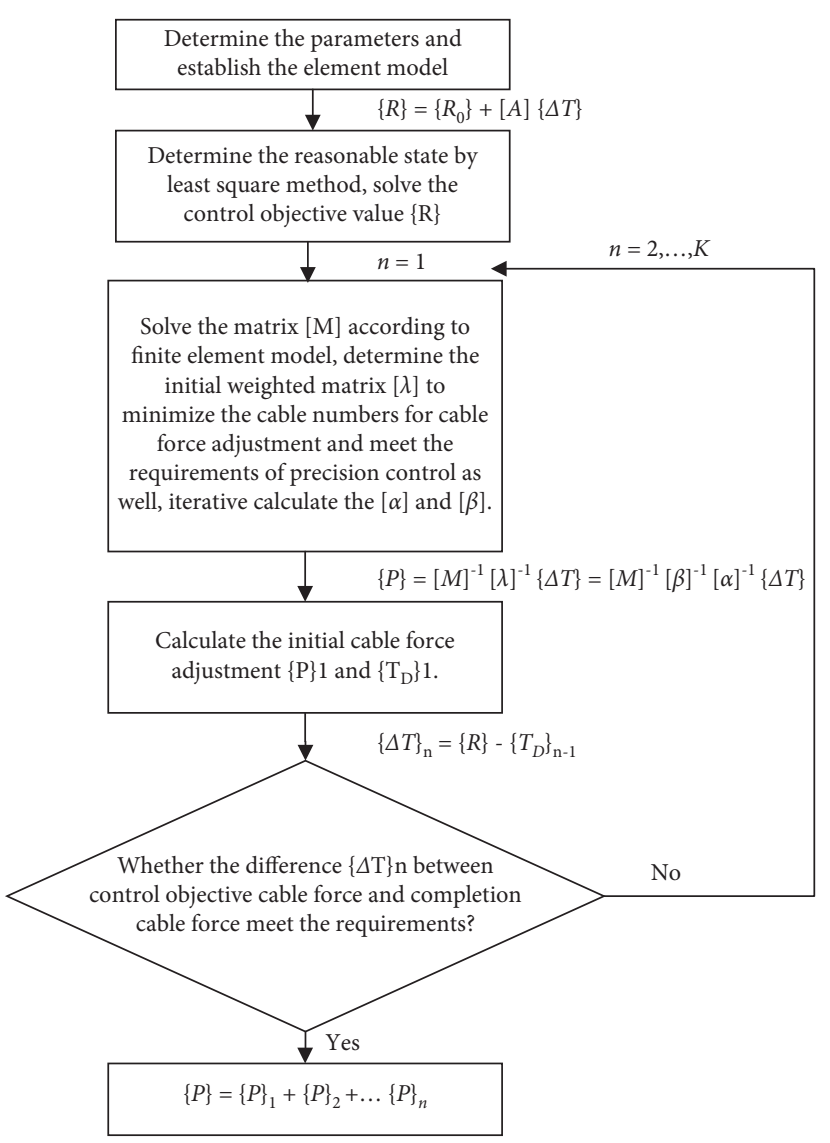

Figure 1: Flowchart of the cable force adjustment.

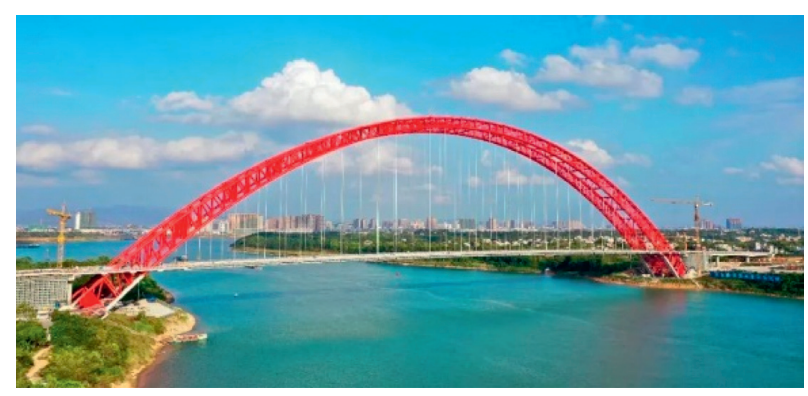

Figure 2: Third Pingnan Bridge.

element. In addition to the dead weight, some detailed structural quality of the structure is also included in the load calculation, and the boundary condition is consolidation at the arch foot. Material characteristics, geometrical parameters, boundary conditions, and the applied external loads are shown in Figure 3. Since the bridge has a symmetrical structure, the single rod suspender number is adopted, and the following assumptions are applied to the model: [1] concrete and steel are ideal elastic materials with fixed elastic modulus; [2] the cross-section deformation conforms to the plane section assumptions; and [3] anticollision wall and guardrail have negligible impact on the bending stiffness of the upper structure. It is assumed that the bending stiffness depends only on the bridge mass. 


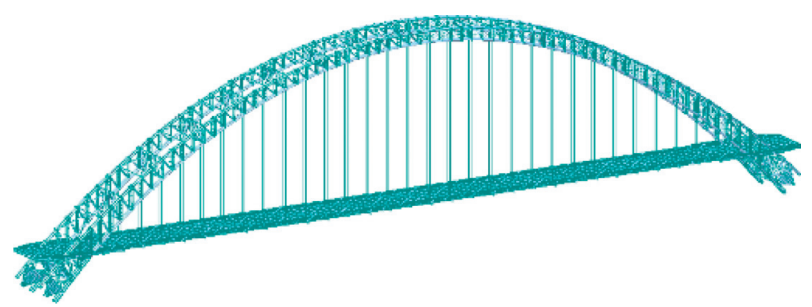

FIgURE 3: Established finite element model.

3.2. Calculating the Influence Matrix. The tension sequence depends on the number of suspenders. When the cable force of each suspender reached $100 \mathrm{kN}$, the influence matrix $[A]$ of other cable forces was calculated. The cable force is measured by vibration measurement method. For suspenders No. 1 6 in the upstream of the south bank as an example, the measured values of suspender cable forces before cable adjustment are shown in Table 1.

According to Table 1, the $\{\Delta T\}$ (difference between the measured cable force and the calculated cable force) is

$$
\{\Delta T\}=\left\{\begin{array}{c}
-137 \\
-49 \\
-39 \\
215 \\
13 \\
73
\end{array}\right\} .
$$

First, the influence matrix is replaced by the impact of single suspender tension on all other suspenders. For suspenders No. 1 6 in the upstream of the south bank as an example, elements of $\Delta \delta_{i j}$ in influence matrix $[M]$ can be represented as shown in

$$
\left[\begin{array}{cccccc}
100 & -61 & -5 & 5 & 3 & 1 \\
-44 & 100 & -57 & -8 & 4 & 3 \\
-3 & -47 & 100 & -53 & -9 & 3 \\
3 & -6 & -45 & 100 & -50 & -10 \\
1 & 3 & -7 & -45 & 100 & -49 \\
0 & 2 & 2 & -8 & -44 & 100
\end{array}\right] .
$$

Through the iterative calculations discussed in Section 2.3 , determine the cable force influence matrix $[M]$ in the model and set the initial weighted matrices such as initial values of $[\alpha]$ and $[\beta]$ matrices as follows:

$$
\begin{aligned}
& {[\alpha]=\left[\begin{array}{cccccc}
0.97 & -0.07 & -0.11 & -0.13 & -0.14 & -0.09 \\
-0.05 & 0.89 & -0.17 & -0.21 & -0.22 & -0.15 \\
0.06 & 0.06 & 1.05 & 0.02 & 0.00 & -0.03 \\
-0.07 & -0.09 & -0.09 & 0.92 & -0.06 & -0.03 \\
-0.09 & -0.18 & -0.19 & -0.17 & 0.88 & -0.06 \\
-0.08 & -0.18 & -0.23 & -0.21 & -0.15 & 0.92
\end{array}\right],} \\
& {[\beta]=\left[\begin{array}{c}
0.00 \\
0.00 \\
0.01 \\
0.02 \\
0.00 \\
-0.09
\end{array}\right] .}
\end{aligned}
$$

According to the formula such as $\{P\}=[M]^{-1}[\beta]^{-1}[\alpha]^{-1}\{\Delta T\}$ in Figure 1, the following results are obtained:

$$
\{P\}=\left\{\begin{array}{l}
0 \\
0 \\
0 \\
1 \\
0 \\
0
\end{array}\right\},
$$

where elements in matrix $\{P\}$ should be multiplied by $100 \mathrm{kN}$

It is found that for the applied load of $100 \mathrm{kN}$, only the suspender S-U-4 should be adjusted, and then the suspender cable force could satisfy the allowable error. The field calculation and measurement values before and after adjustment are shown in Figure 4, indicating that the difference between the cable force and the objective cable force after adjustment is less than $5 \%$.

3.3. Comparative Analysis of Measured Values. According to the practical optimization cable force adjustment method, suspenders of which the cable force deviated from the objective value were calculated and adjusted. To this end, the vibration method was used to test the adjusted cable force. These cables are shown in Table 2. Moreover, the objective control value and the measured value of suspender tension force after completion of the whole bridge are shown in Figure 5.

Table 2 reveals that only 6 suspenders should be adjusted to make the cable force meet the engineering error requirements. In the conventional method of cable force adjustment, 64 suspenders needed adjustment. It is concluded that the proposed method can significantly reduce the workload. The measured cable forces after upstream and downstream the adjustment are shown in Figure 5.

Figure 5 indicates that the construction monitoring of the Third Pingnan Bridge was started when the deck concrete was paved. After adjusting the cable force based on the practical optimal method, the difference between single completion cable force and the theoretical value is less than $5 \%$, and such difference in the cable force of the whole bridge is $1.37 \%$. Moreover, alignments of the arch rib and the bridge deck are generally smooth.

An application example is exhibited by the suspender tension adjustment project of Heshan Hongshui River Bridge (shown in Figure 6) which was constructed in 2021. This bridge is typical CFST (concrete-filled steel tube) with $210 \mathrm{~m}$ span length, and the arch axis coefficient $f$ is 1.45 . Deck of the bridge is supported with 44 steel suspenders that is a link to arch ribs. Each arch rib is uniformly crosssectional concrete-filled steel tube truss. The height and width of each arch rib are $3.8 \mathrm{~m}$ and $2.4 \mathrm{~m}$, respectively. The steel pipe of the main arch rib is made of the steel strand with tensile strength of $1860 \mathrm{MPa}$ and filled with C55 concrete. Because this bridge is a longitudinally symmetric structure, 
TABLE 1: Measured values of suspender cable forces before cable adjustment (suspenders no. 1 6 in the upstream of the south bank).

\begin{tabular}{lcccc}
\hline Code & Number & Initial measured cable force $(\mathrm{kN})$ & Theoretical value $(\mathrm{kN})$ & Deviation $(\%)$ \\
\hline S-U-1 & 1 & 1916 & 1779 & 8 \\
S-U-2 & 2 & 1987 & 1938 & 3 \\
S-U-3 & 3 & 1969 & 1930 & 2 \\
S-U-4 & 4 & 1706 & 1921 & -11 \\
S-U-5 & 5 & 1907 & 1920 & -1 \\
S-U-6 & 6 & 1845 & 1918 & -4 \\
\hline
\end{tabular}

Note. S-U represents the south bank-upstream.

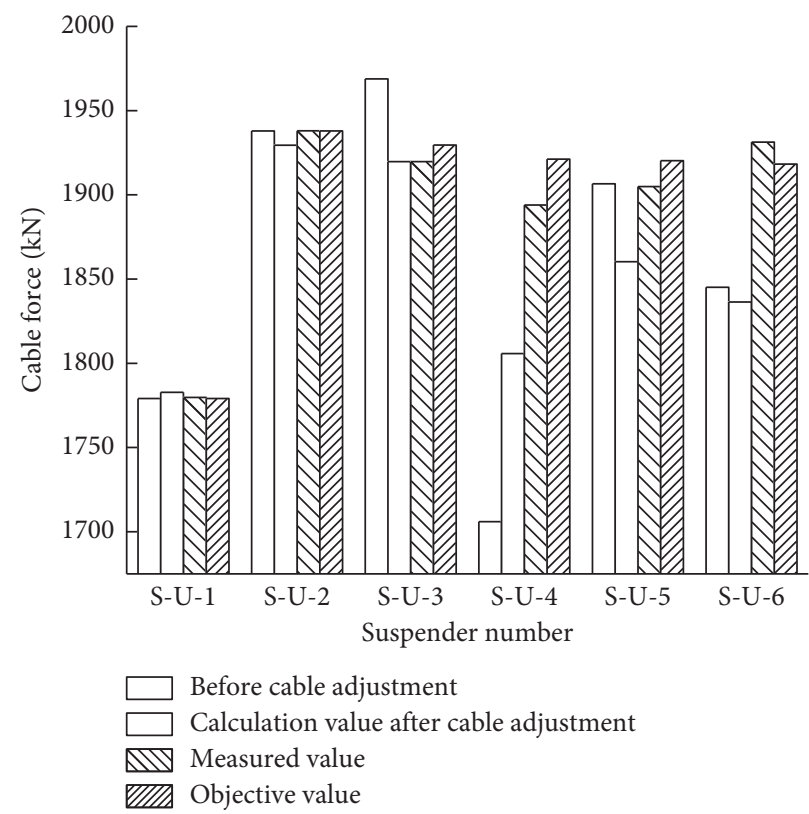

FIgURe 4: Cable forces before and after adjustment (S-U-1 S-U-6).

TABle 2: Adjusted cables and cable forces before and after adjustment.

\begin{tabular}{lccccc}
\hline $\begin{array}{l}\text { Adjust } \\
\text { No }\end{array}$ & $\begin{array}{c}\text { Measured cable force before } \\
\text { adjustment }(\mathrm{kN})\end{array}$ & $\begin{array}{c}\text { Objective cable } \\
\text { force }(\mathrm{kN})\end{array}$ & $\begin{array}{c}\text { Calculated cable force after } \\
\text { adjustment }(\mathrm{kN})\end{array}$ & $\begin{array}{c}\text { Measured cable force after } \\
\text { adjustment }(\mathrm{kN})\end{array}$ & $\begin{array}{c}\text { Deviation after } \\
\text { adjustment }(\%)\end{array}$ \\
\hline S-U-4 & 1706 & 1921 & 1806 & 1894 & 1.4 \\
S-D-3 & 1658 & 1930 & 1853 & 1806 & 1.7 \\
S-D-16 & 1617 & 1807 & 1811 & 1910 & 0.1 \\
N-D-16 & 1525 & 1907 & 1823 & 1971 & -4.6 \\
N-D-15 & 1756 & 1969 & 1948 & 1916 & 0.1 \\
N-D-3 & 2163 & 1927 & 1904 & 196 \\
\hline
\end{tabular}

Note. S-U, S-D, and N-D represent the south bank-upstream, south bank-downstream, and north bank-downstream, respectively.

suspender tension adjustment may start from each side of springers to mid-span, stretching two pairs, four suspenders at once. The finite element model should be established based on each single suspender, to calculate and form the adjustment scheme. The main arch rib steel pipe and web member are simulated by steel pipe elements with different pipe diameters, the suspender is simulated by cable element, and the bridge deck beam is simulated by beam element. In addition to the dead weight, some detailed structural quality of the structure is also included in the load calculation, and the boundary condition is consolidation at the arch foot. The three-dimensional finite element model is formed in Midas
Civil as shown in Figure 7 and the whole model consisted of 1751 nodal points, 70 truss elements, 2678 beam elements, and 360 plate elements. The suspenders are represented with truss elements, and the deck is described by plate elements while others are represented with beam elements.

According to the method in this paper, the tension for each suspender is adjusted based on the computed results. The practical tension is measured by the vibration approach. The measured and designed suspender tensions at completion state of construction are shown in Table 3.

Table 3 reveals that only 10 suspenders should be adjusted to make the cable force meet the engineering error 


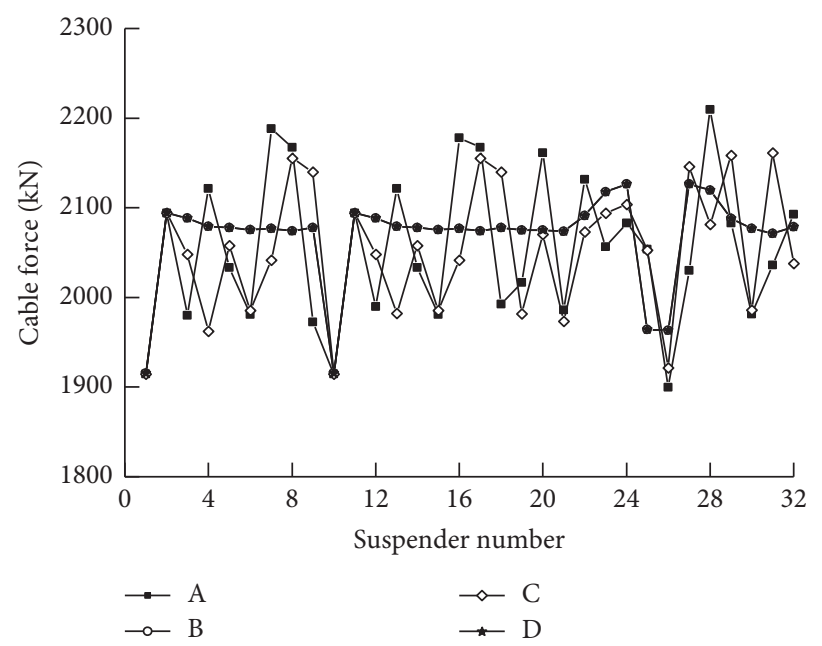

FIGURE 5: Completion cable force after adjustment. (A: cable force measured before upstream adjustment; B: upstream target value; C: measured cable force after downstream adjustment; D: downstream target value).

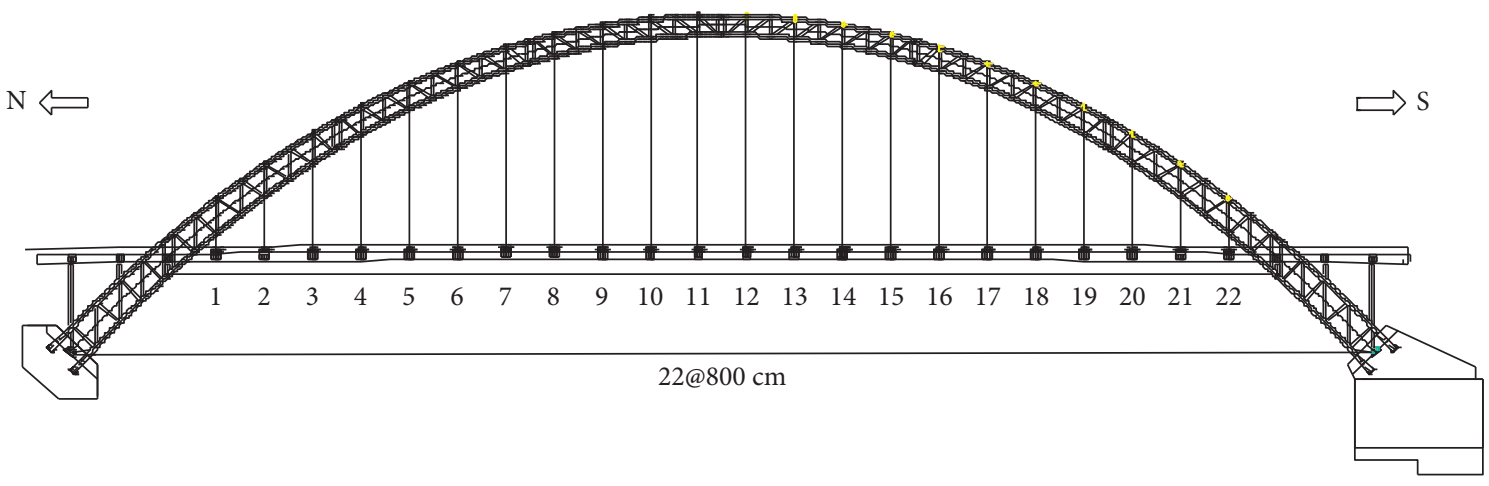

Figure 6: Heshan Hongshui River Bridge.

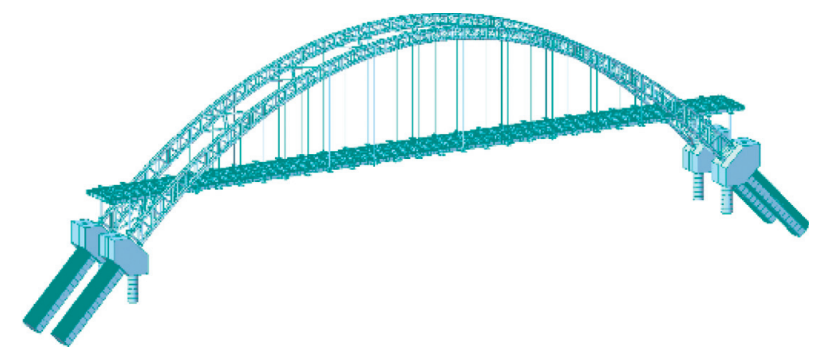

Figure 7: Finite element model of Heshan Hongshui River Bridge. 
TABLE 3: Adjusted cables and cable forces before and after adjustment.

\begin{tabular}{lccccc}
\hline $\begin{array}{l}\text { Adjust } \\
\text { No }\end{array}$ & $\begin{array}{c}\text { Measured cable force before } \\
\text { adjustment }(\mathrm{kN})\end{array}$ & $\begin{array}{c}\text { Objective cable } \\
\text { force }(\mathrm{kN})\end{array}$ & $\begin{array}{c}\text { Calculated cable force after } \\
\text { adjustment }(\mathrm{kN})\end{array}$ & $\begin{array}{c}\text { Measured cable force after } \\
\text { adjustment }(\mathrm{kN})\end{array}$ & $\begin{array}{c}\text { Deviation after } \\
\text { adjustment }(\%)\end{array}$ \\
\hline N-D-1 & 277 & 424 & 427 & 420 & -1.6 \\
N-D-2 & 534 & 454 & 454 & 451 & -0.7 \\
S-U-9 & 482 & 471 & 475 & 469 & -1.3 \\
S-U-11 & 485 & 466 & 485 & 468 & -0.4 \\
S-D-9 & 505 & 462 & 464 & 462 & -0.4 \\
N-U-9 & 507 & 463 & 467 & 454 & -1.1 \\
N-U-11 & 503 & 458 & 462 & 466 & -1.7 \\
N-U-1 & 511 & 471 & 455 & 451 & -0.9 \\
S-D-2 & 573 & 453 & 431 & 424 & -1.6 \\
S-U-1 & 265 & 429 & & \\
\hline
\end{tabular}

Note. S-U, S-D, N-U, and N-D represent the south bank-upstream, south bank-downstream, north bank-upstream, and north bank-downstream, respectively.

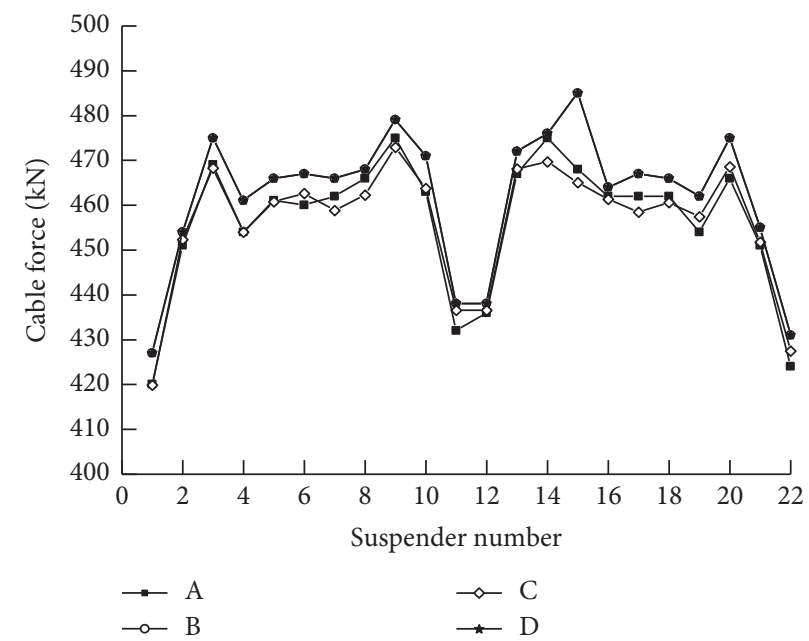

Figure 8: Completion cable force after adjustment. (A: cable force measured before upstream adjustment, B: upstream target value, C: measured cable force after downstream adjustment, D: downstream target value).

requirements. In the conventional method of cable force adjustment, 44 suspenders needed adjustment. It is concluded that the proposed method can significantly reduce the workload. The measured cable forces after upstream and downstream the adjustment are shown in Figure 8.

From the previously mentioned comparison results, the difference between the measured and designed suspender tensions at completion state is less than $2 \%$, which satisfies the engineering requirement.

\section{Conclusions and Recommendations}

In this paper, the suspender tension adjustment for CFST (concrete filled steel tube) is studied when a large difference of suspender tensions between upstream and downstream after the completion of the lattice beams exist. As an improved method of the traditional influence matrix, an adjustment method for the suspender tension of CFST (concrete filled steel tube) based on influence matrix of single suspender is proposed. The proposed method is applied to practical engineering, and the results of theoretical suspender tension adjustment and actual suspender tension adjustment are compared with the design suspender tension value, respectively. From the point of view of the investigation carried out, the following conclusions are reached.

(1) There is a big difference between the measured suspender tensions of upstream and downstream after the completion of the lattice beams, among which the difference of N-D-16 (N-D represent the north bank-downstream in Third Pingnan Bridge) suspender is up to $16 \%$. Therefore, the traditional influence matrix method that only considers the average value of the upstream and downstream suspender tensions will produces large errors.

(2) After this method, the maximum difference between the measured and calculated single cable force of Third Pingnan Bridge is less than 5\%. Moreover, the total cable force difference of Third Pingnan Bridge bridge is $1.37 \%$, and the difference between the measured and designed suspender tensions of Heshan Hongshui River Bridge at completion state is less than $2 \%$, indicating that the calculation accuracy satisfies the requirements of the bridge design. In the 
performed optimization, the requirements of construction and accuracy were considered as the main objectives.

(3) The suspender force adjusted by the improved practical influence matrix method was closer to the control objective suspender force. The complicated process of suspender cable force adjustment by sequence was simplified greatly and that the cable force adjustment of the whole bridge was carried out with fewer cables.

In conclusion, the method proposed in this paper is convenient and feasible in theoretical calculation and can be operated in engineering application as well as meeting the accuracy requirements of engineering.

\section{Data Availability}

The data used to support the findings of this study are included within the article.

\section{Conflicts of Interest}

The authors declare that they have no conflicts of interest.

\section{Authors' Contributions}

Y.M. and Y.X. conceptualized the study; X.K. developed methodology; Y.X. curated the data; X.K and Y.Y. wrote the original draft; and Y.M edited and reviewed the manucript. All authors have read and agreed to the published version of the manuscript.

\section{Acknowledgments}

This study was partly sponsored by the following fund programs: (1) National Natural Science Foundation of China (Code: 51738004); (2) National Natural Science Foundation of China (Code: 51868006); (3) National Natural Science Foundation of China (Code: 51878186); (4) Guangxi Natural Science Foundation Co-Funded Cultivation Project (2018GXNSFAA138067); and (5) Nanning City "Yongjiang Project" Funded Project (2018-01-04).

\section{References}

[1] B. C. Cheng, "Study on the design of $600 \mathrm{~m}$ span concrete arch bridge," Journal of China \& Foreign Highway, vol. 26, no. 3, pp. 21-26, 2016.

[2] J. Salonga and P. Gauvreau, "Comparative study of the proportions, form, and efficiency of concrete arch bridges," Journal of Bridge Eng.vol. 19, no. 4, pp. 3-10, 2014.

[3] Y. Wang, Y. Geng, G. Ranzi, and S. Zhang, "Time-dependent behavior of expansive concrete-filled steel tubular columns," Journal of Constr. Steel Res.vol. 67, no. 3, pp. 471-483, 2011.

[4] S. Li, J. Wang, X. Gao, and C. Yang, "Level 2 safety evaluation of concrete-filled steel tubular arch bridges incorporating structural health monitoring and inspection information based on China bridge standards," Journal of Structural Control and Health Monitoring, vol. 26, no. 3, pp. 23-26, 2019.
[5] Q. Liao and J. M. Xu, "Application of prestressed intelligent tension system in construction of bridges," Journal of Technology of Highway and Transport, vol. 20, no. 4, pp. 102-105, 2005.

[6] J. L. Zheng, J. J. Wang, and T. Mou, "Feasibility study on design and construction of 700m CFST arch bridge," Journal of China Engineering Science, vol. 16, no. 8, pp. 33-35, 2014.

[7] B. C. Cheng and J. G. Wei, "Application of concrete-filled steel tube arch bridge in China: current Status and Prospects," Journal of Civil Engineering, vol. 50, no. 6, pp. 46-50, 2017.

[8] Y. Han, "Research and development of key technologies and key difficulties in the construction of No.3 Bridge in PingNan," Journal of Highway, vol. 10, no. 4, pp. 140-146, 2019.

[9] Z. F. Yang, "Key techniques and innovations in the construction of matan Hongshui river bridge," Journal of Highway, vol. 64, no. 2, pp. 125-129, 2019.

[10] Q. Mao, "Determination of the cable force of the suspension rod of a beam-arch combination bridge," Journal of China \& Foreign Highway, vol. 3, no. 3, pp. 102-104, 2007.

[11] Q. Zhou and J. T. Zhou, "Concrete self-adjusting and pouring method of long-span concrete-filled steel tube arch bridge," Journal of Harbin Institute of Technology, vol. 52, no. 3, pp. 82-89, 2020.

[12] H. Chen and H. S. Wu, "Spatial calculation of suspender tension of pushan tied arch bridge analysis," Journal of Railway Science and Engineering, vol. 5, no. 2, pp. 12-16, 2008.

[13] J. C. Sun, "Summary of calculation methods of tension cable force of suspenders in arch structures," Journal of Structural engineer, vol. 26, no. 4, pp. 154-159, 2010.

[14] Z. Liu, "Determination of the optimal suspender internal force of a tied arch bridge based on the energy method," Journal of Engineering Mechanics, vol. 26, no. 8, pp. 168-173, 2009.

[15] D. H. Yan and G. D. Liu, "The forward installation iteration method to determine the reasonable construction status of cable-stayed bridges," Journal of China Journal of Highway and Transport, vol. 12, no. 2, pp. 59-64, 1999.

[16] H. Fang and Q. Gao, "Application of influence matrix method in cable adjustment of tied arch bridge construction," Journal of China and Foreign Highway, vol. 34, no. 6, pp. 146-148, 2014.

[17] C. K. Gao, H. Jin, and Y. Xu, "Cable force monitoring for the replacement of the suspender of a half-through concrete-filled steel tube arch bridge," Journal of China and Foreign Highway, vol. 34, no. 1, pp. 190-193, 2014.

[18] H. B. Liu, "An adjusting method for the suspender force of continuous beam arch combination bridge based on influence matrix," Journal of Applied Mechanics and Materials, vol. 275, pp. 1082-1085, 2013.

[19] L. L. Wang, H. Wang, L. T. Li, T. Hao, and C. Wu, "An adjustment method for the suspender tension of CFSTTTHAB based on influence matrix of single suspender," Journal of Advances in Civil Engineering, vol. 2020, no. 6, pp. 1-10, Article ID 1232835, 2020.

[20] D. Janjic, "Optimization of cable tensioning in cable-stayed bridges," Journal of Journal of bridge engineering, vol. 2, no. 1, pp. 131-137, 2003. 